\title{
X-Ray Moving Pictures of the Digestive Tract
}

\section{A New Way of Studying Diseases of the Stomach}

\section{By Herbert T. Wade}

AONG the recent advances of medical science none $\mathrm{A}_{\text {has been more marked and conspicuous than prog- }}$ ress in treating the various diseases of the digestive tract, particularly those of the stomach and the intestines. This has been made possible in great measure by modern methods of diagnosis in which quantitative and positive mesults bave been secured in various ways, one and not the least of which has been the study of the digestive tract by means of the Roentgen rays. With the development of improved Roentgen ray tubes and a better understanding of methods for their use a n d application, it was realized that by filling the stomach or digestive tract with material opaque to these rays and making a ritow or radiograph or shadon ture of such a fluid cast in relation to the adjoining organs, the progress of digestion could be studied. This accordingly was done, and to-day in diseases of the stomach and intestines it is quite usual to secure a radiograph or plate on which is recorded such a fluid cast of the stomach and intestines filled with the opaque substance, and then make a Roentgenographic diagnosis.

This opacity is obtained by a mixture of bismuth or barium and buttermilk administered to the patient under examination, and the progress of this material, as it passes from the osophagus in to the stomach and is acted upon by the stomach and then passes out into the intestines, can be studied. Hitherto it has been feasible to take such a radiograph only at various stages of the process, although since the development of motion pictures and motion picture apparatus the desirability of Roentgenokinematographs, or X-ray moving pictures of the stomach, made to demonstrate and record not only the condition, but its actual movements or gastric motor phenomena, has been appreciated and attempts at its realization made. As early as 1909 a series of successive Roentgenograms of the stomach were made by Doctors Kaestle, Rieder, and Rosenthal. Inasmuch as only thirteen of these pictures were made in 22 seconds, it was apparent that while a beginning had been made, with such slow speed true kinematography

hardly could be attained, and the results were little more than an improvement on an ordinary series of Roentgenograms.

Recently, as the result of working on apparatus to make serial radiographs of the stomach and intestines, a special apparatus has been devised by a distinguished Roentgenologist, with which it is now possible to secure true moving pictures on an ordinary sensitized film at various stages of the digestive process at the rate of at least four exposures a second. Thus the churning effect in the stomach and the peristaltic or muscular action in the intestines by which the contents of the alimentary tract are advanced, after being duly acted upon, can be studied by means of motion pictures, which, when reproduced, graphically show by the movement of the silhouetted image the action that is taking place.

This new method has been made possible in large part by the new Coolidge Roentgen ray tube described in the Scientific American of February 21st, 1914, which secures in its operation greater stability and evenness of penetration as well as susceptibility to more accurate regulation, thus giving more even radiographs.

The apparatus for making the moving pictures consists of the usual lead-lined table in a dark booth with the Roentgen ray tube above in the usual position and and

西

as a bone, there will be a corresponding shadow on the fluorescent screen, and the variation in intensity of the shadows of different organs, or material, of course is the basis of the whole operation. The actual effect of the intensifying screen is to emit actinic light under the influence of the Roentgen rays from the tube above. The film itself is not acted upon directly by the Roentgen rays, but by the rays which are sent out from the fluorescent screen. A sec ond fluorescent screen, with its lower surface coated, located directly beneath the first, may be observed by the operator either directly or by means of an inclined mirror. In this way the position of the patient can be arranged so that the stomach can be centered on the film, and, at the same time, the action of the apparatus observed. The operator or the diagnostician can observe the process fluoroscopically and need not start the film in motion until the desired stage is reached.

The film has at its edges regular perforations to engage studs correspondingly placed on the circumfer. ence of sectors connected with the driving mechanism so that it may be moved regularly, but intermittently, across the opening where the shadow falls. The apparatus is arranged so that six exposures a second may be made, and the exposure takes place automatically when a fresh section of the film is placed at the opening. The mechanism operates by means of $\mathrm{sh}$ afts and appropriate gearing, and there is arranged in connection an electric switch that works automatically in conjunction with the advance of the film, closing the circuit of the transformer supplying the alternating current, and lighting up the tube instantaneously as each fresh surface of $t \mathrm{~h} e$ film is brought in position. Accordingly, there is a regular series of exposures of the shadows produced on fresh surfaces of the film and the phenomena occurring in the stomach and intestines can be observed and recorded. In this way, when the film is developed a series of pictures is obtained where the various exposures can be studied both individually and collectively in connection with one another, or they may

Apparatus for taking moving pictures of the stomach.

the customary rotary transformer, or other devices, for its exciting, along with the special mechanism for securing the movement of the film and the periodic exposures. The patient is placed on the table, face downward, with the Roentgen ray tube directly above the stomach. There is a square opening in the table beneath, across which, through suitable guides, the film passes, being wound from one spool to another, as in an ordinary film camera. This film is eight inches in width and is supplied on spools which, as at present constructed, are capable of 25 or 50 exposures. Directly beneath the film is located an intensifying screen coated on its upper side with calcium tungstate, a fluorescent material that glows brilliantly when excited by the Roentgen rays striking its surface. Naturally, when the rays from the tube in their passage through the body encounter any body or substance opaque to them, be reduced by ordinary photographic methods for re-
production in the usual motion picture projection apparatus. The time of the passage of the film can be controlled by the operator and other adjustments made so that the exposures following each other in regular succession make possible a study of the peristaltic action, which is a regular and involuntary muscular contrac tion of the stomach, or intestines, with a period of from 15 to 20 seconds in the case of the stomach. Not only do these motion pictures enable some definite idea to be formed of the peristaltic action taking place in the stomach, but they promise in the future to put at the disposal of the diagnostician, or investigator, additional information regarding peristalis in the pylorus, or lower opening of the stomach. as well as in the upper part of the small intestine, or duodenum. Some twenty-five exposures can be made of 
a single antrum, and sharp and interesting pictures can be obtained.

The mechanical arrangement is indicated in the accompanying illustration, which shows the apparatus as arranged in a modern Roentgen ray laboratory. The operation is practically automatic. Once the patient is in position and the instrument adjusted, a fluoroscopic observation first is made visually, and the film can be rapidly unreeled and the exposures made. After develrapidly unreeled and the exposures made. After devel-
opment the diagnostician has a record of the condition of the gastro-duodenal tract, or the film may be reproduced reduced in size and made available in an ordinary motion picture projection apparatus, so that the record may be thrown upon a screen and the actual motion studied, synchronized to the original time of occurrence. Moving pictures have been applied to a greater or less extent in the study of disease and diagnosis, but this is believed to be the first satisfactory attempt at using them in connection with the Roentgen
rays and with a special and efficient form of apparatus.

A Huge Dipper Dredge for the Panama Canal PON the cover of the present issue we show the
huge dipper of one of the two large hydraulic dredges which have recently been completed for the Panama Canal. The dipper can take up at a single scoop, 15 cubic yards, or say about 20 tons of material, and its huge proportions can be realized from the fact that it has held a group of thirty-four men, standing upon a platform built for the purpose when the photograph was taken.

The two dredges, which are known as "Gamboa" and "Paraiso," have been built at the yards of the Staten Island Shipbuilding Company. Each dredge displaces about 1,500 tons, and each, in addition to its 15-cubic yard bucket, has one other of 10 yards' capacity. It is expected that when in regular service the two dredges
together can take out about 600,000 cubic yards of material per month.

The 15-cubic yard dippers have been built with massive manganese-steel lips and dipper-door hinges of forged steel which are 6 by 10 inches in cross section. The dippers are 10 feet $91 / 2$ inches in height from the bottom band to the upper edge of the lip. They are hung on a $31 / 4$-inch, single-part, wire rope, hoisting cable. The dredges can dig to a depth of 50 feet below the surface of the water.

The dipper handle is 72 feet long, with top and bottom bars measuring 2 inches by 12 inches in cross section. The weight of the dipper handle is 81,000 pounds

The dipper boom is 62 feet long, weighs 113,000 pounds, and is of plate-girder construction. The pins for the sheaves on the boom are 11 inches in diameter. and the parts are larger than any built before for this purpose.

The main hoisting machinery consists of horizontal, twin-tandem, compound, condensing engines, with cylinders 16 and 28 inches in diameter by 24-inch stroke. The engines are compound geared to heavy spur gears about 12 feet in diameter. These gears are mounted on each end of a 16-inch main hoisting shaft which carries the cast steel drum.

There is an independent 12- by 16-inch engine of the link-reverse type for operating the swinging machine.

The spuds at the forward end of the dredge are of unusual size, being 4 feet square and 72 feet long. They are built with cast-steel diaphragms, 5 feet apart and continuous 10-inch I-beams in the middle of each side plate for its full length. The maximum reaction on the spuds when the digging takes place over the side of the dredge is about 700,000 pounds. The spuds are placed sufficiently far back from the front of the dredge to make possible a swing of $\mathbf{1 8 0}$ degrees

\section{The Current Supplement}

THIS week's Supplement brings the concluding instalment of $P$. W. Bridgman's report on his researches
on the properties of water and ice at high pressures.A working model for demonstrating the effects of vege tation as a check to erosion is illustrated and its construction is described.-W. P. Dreaper writes of the research chemist in his relation to the textile industry. -A discussion on the sintering of iron ore, which took place at a recent meeting of the Engineers Society of Western Penusylvania, is reported.-The erosion of canal bottoms by the action of boat propellers has cause much trouble. Prof. O. Flamm has devised means of preventing this, which are described.-F. C. Perkins writes on electrically operated tools.-The third of Sir J. J. Thomson's lectures on Recent Discoveries in Physical Science appears in this issue.-H. Guenther describes the Electro-cardiograph and Its Use.-C. H. Townsend tells us how a school of five live porpoise was brought from Cape Hatteras to the New Yor Aquarium.-F. R. Moulton gives a popular exposition of the solution recently found by Karl F. Sundman for the classical problem of three bodies.
An Innovation in Ship Salvage

\section{By Robert G. Skerrett}

THE salvage of a steamer in grave peril because of a shifted cargo was accomplished a short while ago in a decidedly unique manner. The performance incidentally shows us the naval architect from an unusual angle and, incidentally, illustrates the advantage of technical training when applied elastically.

The craft in danger was a Danish freighter, the steamship "Berlin," bound from Trinidad, with a cargo of nearly 3,000 tons of crude asphalt, and on her wa to New York city. The asphalt was from a new lake, and seemed even at the time of shipping to be somewhat more plastic than the usual run of that substance. It was stowed in the ship's regular cargo space, and aft the hold was divided longitudinally by a center-line bulkhead. However, there was no reason to expect trouble, and all went well until the vessel was some distance on her journey; but then the mischief began in earnest.

Suddenly from the northeast the "Berlin" encountered a heavy gale, and for days the wind blew fiercely, and the seas rose higher and higher as she nosed her way along through the Gulf Stream. She had to slacken speed, but with a sound hull and well-secured hatches there was no apparent cause for alarm. However, the warm waters of the Gulf Stream had been working unnoticed upon the cargo of asphalt, slowly heating it through and making it fluid. Somewhere north of Bermuda the "Berlin" was hit by three exceptionally heavy seas, one after the other, and without any warning the craft quickly heeled over to an angle of 21 degrees and staid there! The surging asphalt had broken the center-line bulkhead away from its fastenings top and bottom at the after end, and this had allowed the argo to shift.

The vessel seemed in imminent peril of turning turtle,

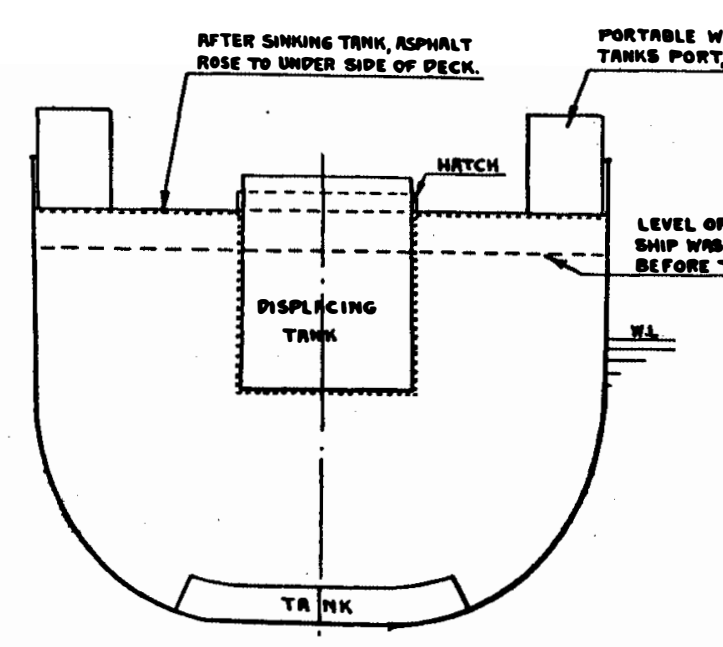

SECT. AT AFT. HOLD

and something had to be done, and done quickly. The engineer's force began the toilsome work of removing the coal from the listed bunkers, while the deck crew and the navigational officers went at the desperate task of trying to secure the upper edge of the ruptured bulkhead. By almost superhuman efforts, lasting well nigh for twenty-four hours, this was effected, but nothing could be done to catch and hold the lower end of the partition. After a fashion, the ship was righted somewhat, but there was still a menace in that loose bottom of the bulkhead.

As the ship rolled toward the side where the bulkhead plating should have been fastened, the partition gave somewhat like a pump leather and allowed the asphalt to surge through the opening toward the listed side. Again, when the ship rolled oppositely, the plating closed the breach and kept the asphalt from flowing back again. Thus, the motions of the vessel and the flexing of the bulkhead acted just like a pump, and raised the level of the threatening fluid four feet higher on one side than on the other. Fortunately, the deck and the hatches held, although the ship had a seriou list, and, after an exhausting struggle, the "Berlin" made harbor at Cape Lookout, North Carolina. Her further relief had then to come from regular salvors. A New York salvage concern that has done some rather remarkable work was asked to bid upon the job of sending a relief vessel to take off a thousand tons of the "Berlin's" cargo, and, together with the Danish craft, to bring both vessels to New York. The asphalt was then far from fluid enough to be pumped out, and to remove by digging would have been a long and a very toilsome, not to say expensive, undertaking. The salvors wanted an easier solution of the pending problem, and just at this stage Mr. R. H. M. Robinson, lately a naval constructor in the United States Navy. was called into consultation. It did not take Mr. Robinson long to figure out that two wooden tanks, one on each side of the upper deck, 5 feet wide and 100 feet long, would hold double the amount of water ballast necessary to trim the ship to an even keel against the listing moment of the unstable cargo. To prevent surging, each tank was subdivided into three compartments, and 131 tons of water were sufficient to right the craft when this ballast was put in the tank on the high side. The idle tank was held in reserve to meet any emergency should the asphaltum shift to the opposite side en route to New York.

But this was not the entire solution of the difficulty and to Mr. C. P. M. Jack, another naval architect of New York, credit is due for the clever means by which the cargo was made to fill the entire hold up to the under side of the deck, and was thus held in place so that it would have no chance to shift again. In one of the big hatches a tank was fitted and loaded until, in sinking, it displaced the asphalt. A crude stuffing box was made out of the cargo hatch coaming, and the displacing tank thus became a weighted hydraulic plunge free to move up and down and to absorb strains that would otherwise have been transmitted to the covering deck

According to the previous, estimates, and counting upon removing a thousand tons of the cargo, it was clear that many days would have been required to get the ship on an even keel again and ready to resume her run northward. But even so, with that work done, there would have been no certainty that the remaining cargo might not have caused more trouble. By the adopted method it took just three days to build the tanks of wood and to fit them in readiness for service The tanks were made of heavy planking lined with tarred paper, and the displacing tank was loaded with bags of sand, sand being a readily obtained material of nature's providing down on the Carolina coast. From the time the salvors started southward from New York until the "Berlin" reached the metropolis under her own steam was a matter of just eleven days.

But for the naval architect's few minutes of figuring, by which he determined how much deck weight moved laterally would be needed to effect the change of trim desired, many days would have been lost in. following the usual procedure in digging out that difficult cargo. Time was saved, money was saved, and a unique remedy was evolved, which may have many pracwas evolved, which may have many prac-
tical advantages in meeting kindred conditions in the future. The ordinary salvor would not have thought of this expedient.

\section{Dried Yeast as a Cattle Food}

G ERMAN breweries are going into the question of $G_{\text {drying yeast with a view to producing food for }}$ stock raising. Such yeast is dried at a rather high heat in cylinders, such as are used for milk powder and for potato drying. The dried yeast contains about 50 per cent of albuminoid matters and forms a concentrated food which can be used to good advantage for most stock when mixed with other foods, and is relished by cows, sheep and horses. With cows, the percentage of butter in the milk is increased, and for horses it is said that half the grain is economically replaced by mixed dried potatoes and dry yeast. Within three years the number of yeast-drying plants increased from 5 to 26 , counting 11 in Germany. It is now introduced for human food, but in this case the yeast is freed as much as possible from the bitter principle due to the hop. Such prepared food is said to be easily digested and assimilated, and Völtz and Baudrexel showed that its value is three times its weight of moderately fat meat. It not only serves for food, but acts very favorably on nutrition owing to the lecithin contained in the proportion of about 2 per cent. According to Hayduck the product, even though it costs $\$ 0.60$ pe pound, costs less than meat for equal food value. It is probable that the price will be lowered when it is produced on a large scale, and no doubt it will be frequently employed in the food industries as a very economical source of albuminoid substances.

\section{Uncorking a Bottle}

I often happens that in attempting to uncork a bottle, the stopper is forced into the bottle instead, and it floats on the liquid. This would perhaps not be were it not that each time the bottle is to be emptied the cork comes to the neck and causes an obstruction, preventing the flow of the liquid. This can be avoided very readily, and all that is needed is to bend a piece of stiff iron wire in a long U-shape, properly fitting it in the neck of the bottle so that the loop por tion projects somewhat below the neck. Upon overturning the bottle, the wire loop prevents the cork from reaching the neck to obstruct it.

\section{Gamma Rays Produced by Roentgen Tube}

A CCORDIng to a special cable dispatch to the Veifa X-ray Tube Works, Frankfurt a. M., has succeeded in producing highly penetrating rays similar to the gamma rays of radium, by means of focus Röntgen tubes. 